\title{
Reporting neural activity with genetically encoded calcium indicators
}

\author{
S. Andrew Hires, Lin Tian and Loren L. Looger* \\ Howard Hughes Medical Institute, Janelia Farm Research Campus, 19700 Helix Dr, Ashburn, \\ VA 20147, USA (*author for correspondence; e-mail: loogerl@janelia.hhmi.org)
}

Received 6 May 2008; Revised 22 June 2008; Accepted 6 August 2008

Published online 22 October 2008

(c) The Author(s) 2008. This article is published with open access at Springerlink.com

\begin{abstract}
Genetically encoded calcium indicators (GECls), based on recombinant fluorescent proteins, have been engineered to observe calcium transients in living cells and organisms. Through observation of calcium, these indicators also report neural activity. We review progress in GECl construction and application, particularly toward in vivo monitoring of sparse action potentials (APs). We summarize the extrinsic and intrinsic factors that influence GECl performance. A simple model of GECl response to AP firing demonstrates the relative significance of these factors. We recommend a standardized protocol for evaluating GECls in a physiologically relevant context. A potential method of simultaneous optical control and recording of neuronal circuits is presented.
\end{abstract}

\section{Introduction}

The intracellular concentration of free divalent calcium ions, $\left[\mathrm{Ca}^{2+}\right]$, is a ubiquitous second messenger that regulates a wide range of cellular functions (Burgoyne, 2007). The magnitude of physiological changes in $\left[\mathrm{Ca}^{2+}\right]$ is uniquely high among all intracellular ions (Hille, 1992). In neurons, action potential (AP) firing triggers large influxes of $\mathrm{Ca}^{2+}$ through voltage-gated calcium channels located throughout the cell (Jaffe et al., 1992). Synaptic input causes local $\mathrm{Ca}^{2+}$ influx through neurotransmitter receptors in dendritic spines and shaft (Muller and Connor, 1991). The spatiotemporal pattern of intracellular $\left[\mathrm{Ca}^{2+}\right]$ is tightly coupled to neural activity (Denk et al., 1996). Therefore, the timing of spikes and patterns of synaptic input can be monitored by observing intracellular $\left[\mathrm{Ca}^{2+}\right]$ (Yasuda et al., 2004; Denk et al., 1996; Yuste and Denk, 1995; Yuste et al., 1999).

Historically, intracellular calcium has been monitored by impaling cells on calcium-sensitive microelectrodes (Rink et al., 1980), by microinjection of bioluminescent proteins (Johnson and Shimomura, 1972), and with synthetic non-fluorescent metallochromic dyes (Tsien and Rink, 1983). The modern era of calcium imaging began with the synthesis of fluorescent dyes based on BAPTA, the highly selective calcium chelator (Tsien, 1980). These include fura (Grynkiewicz et al., 1985), quin (Tsien, 1980), indo (Grynkiewicz et al., 1985), fluo (Minta et al., 1989), and rhod (Minta et al., 1989) dyes. Commercial labs have further diversified these probes (Haugland et al., 2005). Each modern dye has a subset of desirable properties: $\mathrm{Ca}^{2+}$ dependent fluorescence increase of $>100$-fold, high specificity for $\mathrm{Ca}^{2+}$ over other divalent cations, tuned affinity by chlorination or fluorination, fast kinetics, varied excitation and emission spectra, fluorescent intensity or wavelength ratiometric readout, and defined cell permeability (Tsien, 1999). These dyes can reliably quantify the changes in intracellular calcium associated with neural activity (Yasuda et al., 2004). However, 
these small molecule probes have limitations: they can be difficult to introduce into neurons in the intact brain (Kerr and Denk, 2008), they can accumulate in high- $\left[\mathrm{Ca}^{2+}\right]$ intracellular compartments (Di Virgilio et al., 1988), and many are extruded from the cytoplasm in several hours (Di Virgilio et al., 1988). Furthermore, chronic repeated measurements from the same cells in vivo are impossible, and the dyes cannot be targeted to specific cell types, populations, or subcellular locations without added transgenes (Tour et al., 2007).

Genetically encoded calcium indicators (GECls) based on recombinant fluorescent proteins (FPs) address many of the shortcomings of small molecule dyes. GECls can be delivered in a minimally invasive manner to specific cell types or subcellular compartments (Miyawaki et al., 1997). They are compatible with long-term, repeated, in vivo measurements (Hasan et al., 2004). GECls have successfully recorded in vivo neural activity in brain regions with large modulation of dense spiking (Kerr et al., 2000; Fiala et al., 2002; Hasan et al., 2004), though recording of sparse spike trains remains elusive (Mank and Griesbeck, 2008). Through iterative cycles of optimization, GECls are now able to occasionally detect single APs, at least under ideal ex vivo imaging conditions (Mao et al., 2008). Once single-AP detection can be consistently achieved in vivo, GECls will revolutionize analysis of neural circuit dynamics. However, at their current state of development, GECls still have significant drawbacks. The best GECls remain inferior to synthetic dyes in signal-to-noise (SNR), kinetics, linearity, photostability, and ion selectivity (Mank and Griesbeck, 2008; Tsien, 1999). Of additional concern in vivo, GECls can bind and interfere with endogenous signaling molecules (Hasan et al., 2004; Palmer and Tsien, 2006), and protein stability and fluorescence properties often suffer at physiological temperatures (Nakai et al., 2001).

Since proper application of GECls requires a significant investment in time and resources, selection of the most appropriate $\mathrm{GECl}$ at the start of a project is paramount. Previous reviews have outlined strategies for $\mathrm{GECl}$ construction (Miyawaki and Tsien, 2000; Mank and Griesbeck, 2008), optimization (Shimozono and Miyawaki, 2008), and expression (Kotlikoff, 2007). Detailed protocols for quantitative calcium measurement with GECls are available (Palmer and Tsien, 2006; Kerr and Schafer, 2006; Truong et al., 2007). Comparisons of GECl performance have been made in mouse brain slice (Pologruto et al., 2004; Mao et al., 2008), Drosophila larval neuromuscular junction (Reiff et al., 2005; Mank et al., 2006), and intact mouse brain (Hasan et al., 2004). In this paper, we analyze factors that affect GECl performance, specifically for detection of neural activity, and predict how future optimization will improve this performance. This information can guide GECl selection.

\section{GECI construction strategies}

A GECl comprises a calcium-binding recognition element allosterically coupled to an optical reporter element. Most GECl recognition elements are based on naturally evolved calcium-binding proteins with large $\mathrm{Ca}^{2+}$-dependent conformational changes such as calmodulin (CaM) (Miyawaki et al., 1997; Nakai et al., 2001) or troponin-C (TnC) (Heim and Griesbeck, 2004). Wild-type recognition elements have been engineered to improve binding and response properties (Palmer et al., 2006; Garaschuk et al., 2007). Many GECls use a conformational actuator to magnify the $\mathrm{Ca}^{2+}$. dependent conformational change. The classical example is the M13 peptide (M13pep) from myosin light chain kinase, which preferentially binds to the calcium-bound form of calmodulin (Miyawaki et al., 1997).

There are two classes of $\mathrm{GECl}$ reporter elements: single fluorescent proteins (FPs) or Fluorescence Resonance Energy Transfer (FRET) donor-acceptor FP pairs. Single-FP reporter elements typically comprise a circularly permuted or split FP whose fluorescence properties (emission wavelength or intensity) are modulated by recognition element-dependent changes in chromophore protonation state or strain (Baird et al., 1999; Nagai et al., 2001; Nakai et al., 2001). In 2-FP GECls, conformational changes in the recognition element modulate FRET transfer efficiency between the FP pair, altering the emission intensity of both donor and acceptor (Miyawaki et al., 1997; Heim and Griesbeck, 2004). The molecular architecture of several representative GECls is shown in Fig. 1. 
Hires et al.
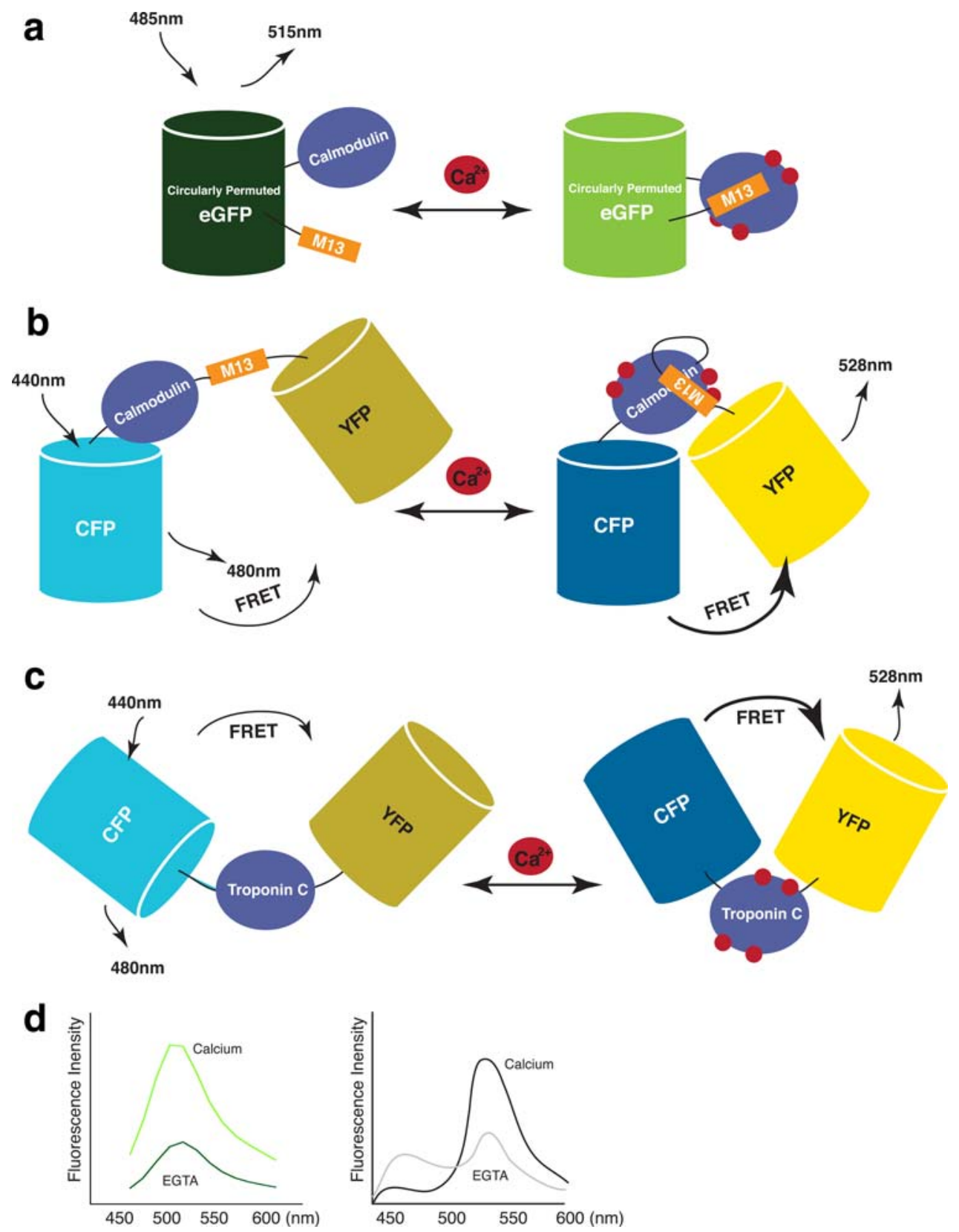

Fig. 1. Schematic representation of several commonly used genetically encoded $\mathrm{Ca}^{2+}$ indicators (GECls). GECls are based either on change of florescence of a single fluorophore (a) or change in fluorescence resonance energy transfer (FRET) efficiency (b, c). (a) Schematic of G-CaMP sensing mechanism. Upon calcium binding, conformational change of CaM and formation of the CaM-M13pep complex increases the fluorescence of the circularly permuted GFP. (b) The cameleon family of FRET-based GECls, in which CaM and the M13 peptide are bracketed by a FRET pair. Calcium binding to calmodulin increases emission from the FRET acceptor. (c) Troponin-based FRET GECls, in which the skeletal muscle calcium sensor troponin-C $(T n C)$ is bracketed by a FRET pair. Binding of calcium to TnC leads to a conformational change and an increase in FRET acceptor emission. (d) Schematic representations of the fluorescence change for GCaMPs (left) and FRET indicators (right). In (b) and (c), CFP and YFP represent generic FRET donors and acceptors. These may be engineered or circularly permuted versions of eCFP and eYFP, or they may be alternate fluorescent proteins. 


\section{Performance of current GeCls}

The challenge of using GECls for functional neuronal imaging can be illustrated by comparing the performance of a state-of-the-art GECI, G-CaMP2, to that of a simultaneously recorded intracellular synthetic dye, X-Rhod-5F (Fig. 2a). In response to high-frequency trains of APs (40AP at $83 \mathrm{~Hz}$ ), G-CaMP2's change in fluorescence over baseline $\left(\Delta F / F_{0}\right)$ slightly exceeds that of $X-R h o d-5 F$. However, during briefer trains, the GECl response is relatively small. A single AP can be reliably detected with the synthetic indicator but not with the GECl (Fig. 2a) (Mao et al., 2008). The SNR of the measurement is defined by the ratio of the signal change $\left(\Delta F=F_{\text {obs }}-F_{0}\right.$; where $F_{\text {obs }}$ is sensor fluorescence at peak $\left[\mathrm{Ca}^{2+}\right], F_{0}$ is sensor fluorescence at baseline $\left.\left[\mathrm{Ca}^{2+}\right]\right)$ to the shot noise of baseline fluorescence $\left(\sim F_{0} N^{-1 / 2}\right)$ such that

$$
\mathrm{SNR}=\frac{\Delta F}{F_{0}} N^{1 / 2}
$$

where $N$ is the number of photons detected (Yasuda et al., 2004). The dye has a noise level approximately 10 -fold lower than the GECI. Although $X-R h o d-5 F$ is much dimmer than GFP (rhod-2's $E C \times Q E \approx 8,300$ at saturating calcium vs. 33,000 for EGFP), it has a relatively low affinity, one binding site, does not bind endogenous proteins and is acutely introduced. Therefore, it can be used at much higher concentrations than G-CaMP2, reducing noise. There is also a large degree of cell-to-cell variability in GECl response magnitude and apparent kinetics (Figs. 2b and $3 a$ ) (Mao et al., 2008), which could cause considerable detection bias when imaging networks of interacting neurons. The basis of this variability remains under investigation.

\section{Extrinsic properties that influence the performance of GECls}

\section{$\mathrm{Ca}^{2+}$ dynamics}

An in vivo AP lasts approximately $1 \mathrm{~ms}$, with a rapid influx of $\mathrm{Ca}^{2+}$ occurring during the repolarization of the neuron back to baseline (Llinas et al., 1982). Calcium is actively extruded over a significantly longer period (Markram and Sakmann, 1994). The precise time course is dependent on subcellular location, accessible volume, extrusion machinery, temperature, and the buffering capacity of the cytosol (and calcium indicator, if present). A broad time course allows more complete calcium binding to GECls, increasing $\Delta F$. Photons can be collected over a longer period than the underlying voltage spike, increasing $N$. It also lowers the sampling rate necessary to accurately capture the transient time course (Kerr and Denk, 2008). This allows simultaneous recording of spatially segregated calcium signals with single point excitation, as in two-photon laser scanning microscopy (2PLSM).

Action potentials occur at a wide range of frequencies. When sparse, each calcium transient is independent. When closely spaced, the calcium transients sum (Helmchen et al., 1996). Since the SNR of a GECl is generally insufficient to resolve a single AP (Mao et al., 2008), summation of closely spaced APs is necessary for GECl-based detection of neuronal spiking. Threshold effects make the interpretation of the absence of response problematic. For imaging data to be meaningful, the relationship between AP frequency and fluorescence response must be calibrated by simultaneous electrophysiology (Jayaraman and Laurent, 2007).

For a single AP, the change in free intracellular calcium $\Delta\left[\mathrm{Ca}^{2+}\right]_{i}(t)$ can be expressed as a function of the resting calcium level $\left[\mathrm{Ca}^{2+}\right]_{0}$, the total amount of calcium current injected by the AP $\Delta\left[\mathrm{Ca}^{2+}\right]_{\mathrm{T}}$, the calcium extrusion rate $(\gamma)$ and the buffering capacity of the endogenous buffers $\left(\kappa_{\mathrm{S}}\right)$ and the $\mathrm{GECl}\left(\kappa_{\mathrm{B}}\right)$. Buffering capacity is defined as $\Delta\left[\mathrm{Ca}^{2+}\right]_{\mathrm{T}} / \Delta\left[\mathrm{Ca}^{2+}\right]_{\mathrm{i}}$ and has been empirically determined in many cell types (Neher, 1995). The differential equations governing AP-mediated calcium transients have been explicitly solved (Neher, 1995; Helmchen et al., 1996). Prior to an AP $(t<0), \Delta\left[\mathrm{Ca}^{2+}\right]_{\mathrm{i}}=0$ and $\left[\mathrm{Ca}^{2+}\right]_{\mathrm{i}}=\left[\mathrm{Ca}^{2+}\right]_{0}$. Immediately following an $\mathrm{AP}$ the calcium level spikes and subsequently decays such that:

$$
\begin{gathered}
\Delta\left[\mathrm{Ca}^{2+}\right]_{\mathrm{i}}=A \cdot e^{-t / \tau} \\
\tau=\frac{1+\kappa_{\mathrm{S}}+\kappa_{\mathrm{B}}}{\gamma} \\
A=\frac{\Delta\left[\mathrm{Ca}^{2+}\right]_{\mathrm{T}}}{1+\kappa_{\mathrm{S}}+\kappa_{\mathrm{B}}}
\end{gathered}
$$

In the case of a typical Layer $V$ cortical pyramidal neuron measured near the base of the 

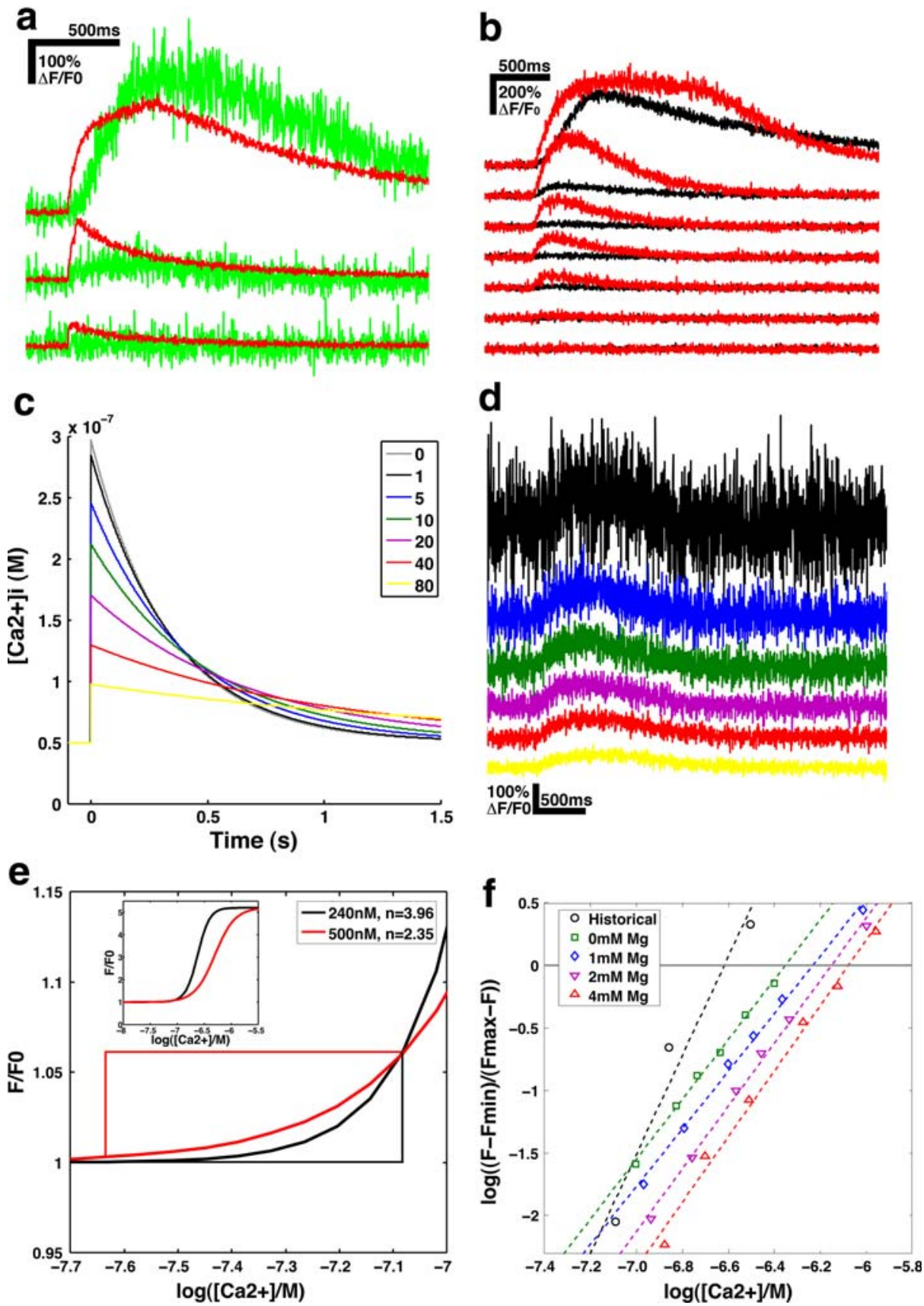

Fig. 2. Properties that shape $\mathrm{GECl}$ response. (a) Typical fluorescence response of a G-CaMP2-expressing cell loaded with $500 \mu \mathrm{M}$ $\mathrm{X}$-Rhod-5F. Trains of 1,5 , and $40 \mathrm{AP}$ delivered at $83 \mathrm{~Hz}$ by a whole-cell patch pipette. G-CaMP2 response in green, X-Rhod-5F response in red. (b) Variation of G-CaMP2 response to trains of 1, 2, 3, 4, 5, 10, and 40 APs, between two cells (red) and (black) of similar brightness, whole-cell parameters, and apparent health. (c) Increasing model [GECl] between $0,1,5,10,20,40,80 \mu \mathrm{M}$ lowers the peak $\Delta\left[\mathrm{Ca}^{2+}\right]_{\mathrm{i}}$ transient and lengthens its time course. Model temperature is $22^{\circ} \mathrm{C} ; \tau \approx 330 \mathrm{~ms}$ for the $0 \mu \mathrm{M}$ case. (d) Increasing [GECI] improves the model's SNR at $10 \mathrm{AP}$ despite lowering peak $\Delta\left[\mathrm{Ca}^{2+}\right]_{i}$. Colors as in c. (e) Sensitivity of $F_{0}$ to the range of $\left[\mathrm{Ca}^{2+}\right]_{0}$ in healthy neurons (23-83 nM). Affinity estimates derived from in vitro titrations of G-CaMP2 in historical buffer (black) or mock internal solution with 0.5 mM free $\mathrm{Mg}^{2+}($ red $)$. Inset shows titration over larger $\left[\mathrm{Ca}^{2+}\right]$ range. (f) Titrations of G-CaMP2 in historical buffer or in mock internal solution with $0-4 \mathrm{mM} \mathrm{Mg}^{2+}$. 

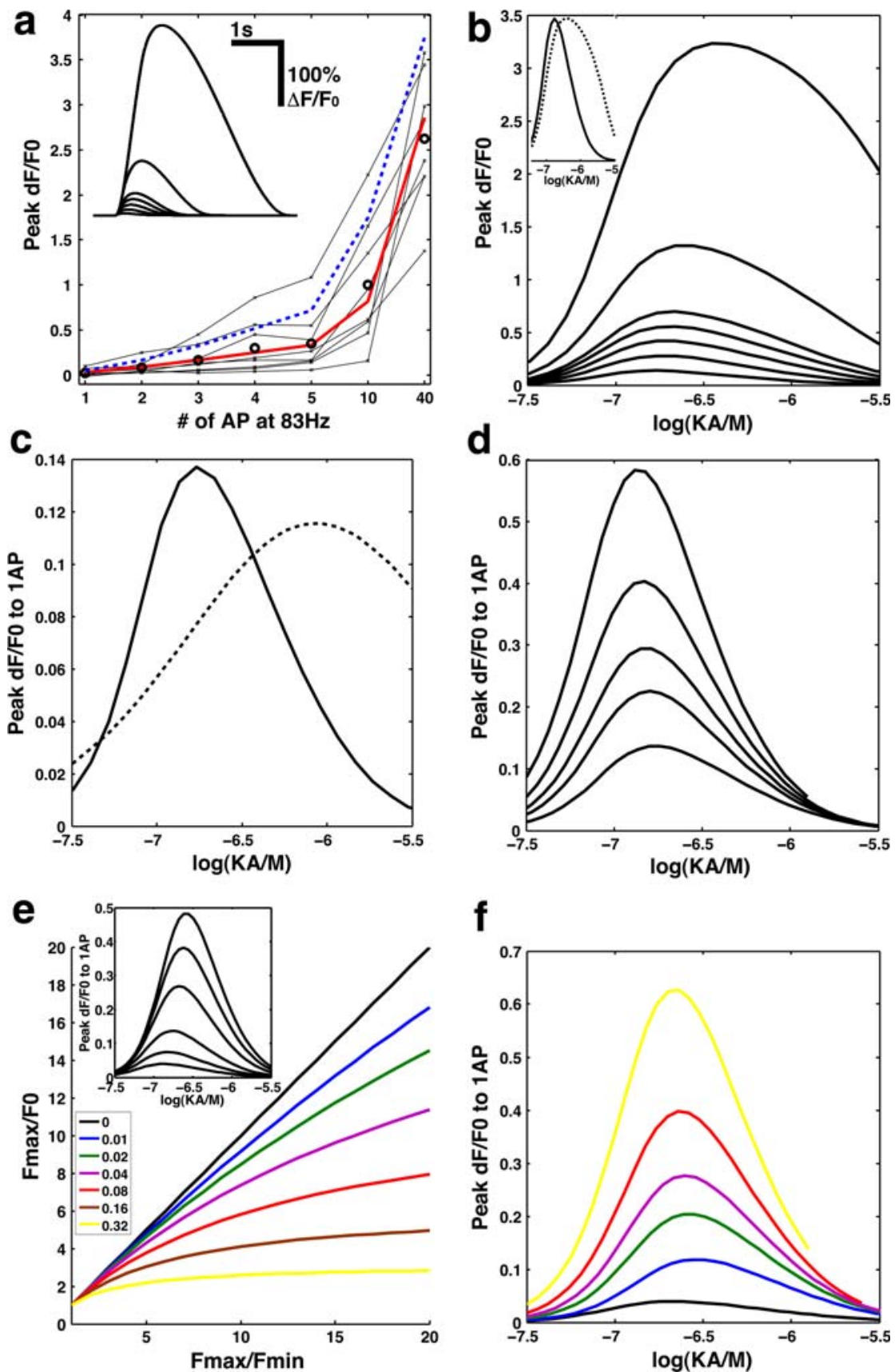

Fig. 3. (a) Comparison of GECl model's peak $\Delta F / F_{0}$ (red line) for $1,2,3,4,5,10$, and $40 A P$ trains to individual G-CaMP2 responses (thin lines) and the mean G-CaMP2 response (black circles). Increasing model $k_{\text {on }}$ and $k_{\text {off }} 5$-fold (blue dotted line) increases response. (a, inset) Model fluorescence time course. (b) Predicted peak change in fluorescence over baseline to AP trains $(1,2,3,4,5,10,40)$ for a range of $K_{\mathrm{A}}$ values. (b, inset) $1 \mathrm{AP}$ (solid) and 40AP (dotted) trains normalized to optimal response. (c) Optimal affinity for $1 \mathrm{AP}$ response shifts between $n=2.5$ (solid) and $n=1$ (dotted). (d) Model response to 1 AP increases with kinetic rates $k_{\text {on }}=(0.8,1.6,2.4,4$, and 8$) \times 10^{6}$. (e) The dependence of effective dynamic range on total dynamic range is reduced as fractional saturation of model $\mathrm{GECl}_{\text {at }}\left[\mathrm{Ca}^{2+}\right]_{0}$ increases from 0 to 0.32 . (e, inset) Increasing total dynamic range $\left(F_{\max } / F_{\min }=2,3,5,10,15,20\right)$ shifts the optimal $K_{\mathrm{A}}$ for single AP detection from 130 to $260 \mathrm{nM}$. (f) Responses to 1AP when time course of calcium transient decay is decreased to $70 \mathrm{~ms} . n=2.5, k_{\mathrm{on}}=8 \times 10^{5} \mathrm{M}^{-1} \mathrm{~s}^{-1}, F_{\text {max }} /$ $F_{\text {min }}=5$ (black), $k_{\text {on }}=(8,16,32,40$, and 80$) \times 10^{5} \mathrm{M}^{-1} \mathrm{~s}^{-1}, F_{\max } / F_{\min }=15$ (colors). 
apical dendrite, $\kappa_{S} \approx 125$ and baseline $\left[\mathrm{Ca}^{2+}\right]_{0} \approx 50 \mathrm{nM}$. In the absence of a perturbing indicator, peak $\Delta\left[\mathrm{Ca}^{2+}\right]_{\mathrm{i}} \approx 250 \mathrm{nM}$ and $\tau \approx 70 \mathrm{~ms}$ per AP at $37^{\circ} \mathrm{C}$ (Helmchen et al., 1996). During brief trains, calcium fluxes from APs sum linearly (Helmchen et al., 1996). At room temperature, $\tau$ increases $\sim 5$-fold, due to slowed calcium extrusion, while peak $\Delta\left[\mathrm{Ca}^{2+}\right]_{\mathrm{i}}$ increases only slightly (Markram et al., 1995).

\section{Intrinsic properties that influence the performance of GeCls}

\section{GECl expression levels}

Fluorescence response of a $\mathrm{GECl}$ requires $\mathrm{Ca}^{2+}$ binding by the recognition element, thus GECls inherently perturb calcium dynamics. Excessive [GECI] will significantly buffer AP-evoked calcium transients. Expression of high affinity cameleons in Caenorhabditis elegans buffers sufficient calcium (Suzuki et al., 2003) to affect behavior (Kindt et al., 2007) and rescues calcium-binding protein knockout phenotypes (Ferkey et al., 2007). To minimize GECl effects on the transient, $\kappa_{\mathrm{B}}$ should be significantly less than $\kappa_{\mathrm{S}}$. However, raising [GECl] also improves SNR proportional to [GECI] ${ }^{1 / 2}$ by increasing the number of photons collected, see Eq. 1 (Yasuda et al., 2004). The optimal [GECl] for an experiment strikes a balance between SNR and buffering.

The buffering capacity of an exogenous buffer is defined by its affinity, concentration, and resting intracellular $\left[\mathrm{Ca}^{2+}\right]_{0}$ (Neher, 1995) such that

$$
\kappa_{\mathrm{B}}=\sum_{\mathrm{Ca}^{2+} \text { sites }} \frac{\left[\mathrm{Ca}^{2+} \text { site }\right] \cdot K_{\mathrm{d}, \mathrm{i}}}{\left(K_{\mathrm{d}, \mathrm{i}}+\left[\mathrm{Ca}^{2+}\right]_{0}\right)^{2}}
$$

where $K_{\mathrm{d}, \mathrm{i}}$ is the dissociation constant $\left(K_{\mathrm{d}}\right)$ of each $\mathrm{Ca}^{2+}$-binding site. For a hypothetical GECl with four equivalent sites of $K_{\mathrm{d}}=1 \mu \mathrm{M}$ at $\left[\mathrm{Ca}^{2+}\right]_{0}=50 \mathrm{nM}, \kappa_{\mathrm{B}} \approx 1.32 \times 10^{7} \mathrm{M}^{-1}$. [GECl]. Increasing [GECl] will spread the free calcium over a longer-time period and lower the peak of the observed transient (Fig. 2c). The effect of [GECI] on SNR is illustrated by the hypothetical output of a model $\mathrm{GECl}$ to a $10 \mathrm{AP}$ train at different [GECl] (Fig. 2d).

Assessment of the proper GECl expression level requires quantitative estimates of the relative expression of $\mathrm{GECl}$ to endogenous buffering capac- ity. This is most easily done by comparing fluorescence of purified GECl to intracellularly expressed GECl under identical imaging conditions (Tour et al., 2007). For FRET reporters, the emission of directly excited acceptor chromophore is used, as this is insensitive to calcium levels (Miyawaki and Tsien, 2000). For ratiometric single-FP sensors, the fluorescence isoemission wavelength, the point where emission intensity is insensitive to calcium, can be used. For intensity-modulated single-FP sensors, $\left[\mathrm{Ca}^{2+}\right]_{i}$ must be independently measured or approximated, and corrected for. Resting calcium in healthy cortical pyramidal neurons at room temperature is approximately $53 \pm 30 \mathrm{nM}$ (Schiller et al., 1995). Using two different in vitro estimates of G-CaMP2 affinity and these $\left[\mathrm{Ca}^{2+}\right]_{0}$ values, $F_{0} \approx F_{\text {min }}$. The variation in [GECl] estimate due to variation in $\left[\mathrm{Ca}^{2+}\right]_{0}$ is limited to $\sim 5 \%$ (Fig. 2e).

In cultured HeLa cells, concentrations of YC3.1 below $20 \mu \mathrm{M}$ were too dim for single cell imaging (Miyawaki et al., 1999). More sensitive GECls, GCaMP2 and YC3.60, have been used with epifluorescence illumination at $1.6 \mu \mathrm{M}$ in mouse heart cytosol (Kotlikoff, 2007) and $1 \mu \mathrm{M}$ in plant guard cells (Yang et al., 2008), respectively. In our study, using 2PLSM of acute cortical slices, [G-CaMP2] in recorded cells was $9.3 \mu \mathrm{M}$ (std. dev. $=3.7 \mu \mathrm{M}$ ). Cells with [G-CaMP2] below $5 \mu \mathrm{M}$ required unacceptably high laser intensity. Cells with [G-CaMP2] above $20 \mu \mathrm{M}$ had attenuated responses for low AP bursts.

Misfolded or non-fluorescent GECls may contribute to additional calcium buffering. A stoichiometric standard insensitive to calcium, such as a linear fusion to a reference FP, could be used to confirm [GECI], provided the standard did not perturb the function of the reporter. Alternative strategies include simultaneous translation of a reference FP using IRES (Pelletier and Sonenberg, 1988) or 2A peptide (Furler et al., 2001), and quantitative immunostaining.

\section{Interference with endogenous $\mathrm{Ca}^{2+}$ signaling} In addition to buffering $\mathrm{Ca}^{2+}, \mathrm{GECl}$ components (e.g., CaM, M13pep) may be sequestered by host proteins, resulting in higher fluorescence background and possible interference with development and signaling. Early attempts to target yellow cameleons to the plasma membrane resulted in non-functional indicators (Heim and Griesbeck, 2004), while generation of transgenic mice expressing yellow cameleons (YC3.0 and YC3.12, 
respectively) under a constitutive (Tsai et al., 2003) and tetracycline-inducible promoter (Hasan et al., 2004) failed to show functional responses in vivo. Camgaroo2 and inverse pericam showed very modest responses when expressed under the inducible promoter system (Hasan et al., 2004). Fluorescence-recovery-after-photobleaching experiments indicated that half of the expressed inverse pericam was immobile (Hasan et al., 2004). These failures were attributed to interference, and inspired efforts to engineer probes orthogonal to endogenous calcium signaling molecules.

One approach to avoid endogenous interference was to substitute troponin-C, a skeletal calcium sensor not normally expressed in neurons, for calmodulin (Heim and Griesbeck, 2004). These $\mathrm{GECl}$ derivatives showed functional responses in vivo and form the basis of a major GECl class (e.g., TN-L15, TN-XL, TN-XXL) (Garaschuk et al., 2007; Mank and Griesbeck, 2008). Another strategy was the reengineering of the CaM-M13pep interface of yellow cameleons to favor intra- over inter-molecular interactions. These sensors (D1, D2cpv, D3cpv, and $\mathrm{D} 4 \mathrm{cpv}$ ) functioned when targeted to the plasma membrane and reliably reported calcium transients from single field stimulations in cultured hippocampal neurons (Palmer et al., 2006). In addition to increasing the proportion of functional $\mathrm{GECl}$, the removal of interference may allow much higher levels of GECI expression in vivo, improving SNR.

\section{GECI affinity}

The sensitivity of a GECl is critically dependent on sensor affinity, kinetics and dynamic range, which influence responses to calcium transients in an interdependent way. Quantitative measurement of $\left[\mathrm{Ca}^{2+}\right]$ is impossible without reliable estimates of all three parameters. The reported affinity of a single $\mathrm{GECl}$ can vary as much as 8-fold between in vitro and in situ titrations (Nakai et al., 2001; Pologruto et al., 2004). Discrepancies are likely due to differences in the biochemical milieu of the assay (Pologruto et al., 2004). lonic strength can dramatically affect the maximum ratio change of FRET reporters (Hires et al., 2008) or the apparent affinity of the ligand-binding domain. Calmodulin's calcium affinity is reduced $\sim 3$-fold when assayed in $150 \mathrm{mM}$ vs. $100 \mathrm{mM}[\mathrm{KCl}]$ (Linse et al., 1991), and both affinity and apparent cooperativity are reduced with increasing $\left[\mathrm{Mg}^{2+}\right]$ (Ogawa and Tanokura, 1984).

Pipette internal solutions typically have ionic strength of $\sim 0.17$, yet nearly all published in vitro measurements on GECls, including yellow cameleons (Miyawaki et al., 1997, 1999), reengineered cameleons (Palmer et al., 2006), pericams (Nagai et al., 2001), camgaroos (Baird et al., 1999), troponin-C based indicators (Mank et al., 2006), and G-CaMPs (Nakai et al., 2001; Ohkura et al., 2005) have been made in buffers with only 0.085 0.135 ionic strength $(50-100 \mathrm{mM} \mathrm{KCl}$ or $\mathrm{NaCl})$. Internal free $\left[\mathrm{Mg}^{2+}\right]$ ranges from 0 to $4 \mathrm{mM}$, yet $\left[\mathrm{Mg}^{2+}\right]$ dependence has only been seriously investigated in troponin-based GECls (Heim and Griesbeck, 2004; Mank et al., 2006).

We tested the effects of ionic strength, $\mathrm{pH}$, and magnesium on GECls, measuring the response of G-CaMP2 to calcium in a historical buffer $(100 \mathrm{mM}$ $\mathrm{KCl}, 30 \mathrm{mM}$ MOPS, $10 \mathrm{mM} \mathrm{K} \mathrm{K}_{2}$ EGTA/CaEGTA, $\mathrm{pH}=7.50)$, and mock internal solutions $(135 \mathrm{mM}$ $\mathrm{KCl}, 0-4 \mathrm{mM} \mathrm{MgCl} 2,10 \mathrm{mM}$ HEPES, $3 \mathrm{mM} \mathrm{Na}-$ ascorbate, $10 \mathrm{mM} \mathrm{K} \mathrm{K}_{2} \mathrm{EGTA} / \mathrm{CaEGTA}, \mathrm{pH}=7.30$ ). The historical buffer titration gave values (calcium concentration at half-maximal fluorescence change, $K_{\mathrm{A}}=240 \pm 45 \mathrm{nM}$; apparent Hill coefficient, $n=3.96 \pm 0.09$; dynamic range, $F_{\max }$ $\left.F_{\min }=3.93 \pm 0.09\right)$ in agreement with previous measurements (M. Kotlikoff, personal communication). However, G-CaMP2 in mock internal solution exhibited much weaker affinity, reduced cooperativity, and higher dynamic range. Increasing $\left[\mathrm{Mg}^{2+}\right]$ decreased apparent calcium affinity and dynamic range $\left(K_{\mathrm{A}}=443 \pm 13,584 \pm 30,704 \pm 37\right.$, $835 \pm 71 \mathrm{nM} ; n=2.39 \pm 0.013,2.31 \pm 0.024$, $2.51 \pm 0.024,2.62 \pm 0.038 ; \quad F_{\mathrm{max}} /$ $F_{\min }=6.42 \pm 0.22,6.25 \pm 0.05, \quad 5.81 \pm 0.07$, $5.50 \pm 0.08$ for $\left[\mathrm{Mg}^{2+}\right]=0,1,2,4 \mathrm{mM}$ ) (Fig. 2f).

Since similar binding mechanisms govern GECl signaling, the results from G-CaMP2 are likely general to other CaM-based GECls. The accuracy of intracellular $\left[\mathrm{Ca}^{2+}\right]$ measurement with GECls could be improved by using affinity constants determined in the specific intracellular solution used in the patch pipette, or in a buffer that reflects cytosol if cell membrane-intact recording methods are used. Ideally, affinities should be confirmed with simultaneous in situ imaging of a synthetic dye (Pologruto et al., 2004). Since membrane-intact, in situ calibrations are inherently dynamic measurements, GECl kinetics must be considered for accurate in situ affinity estimates.

\section{GECI kinetics}

Neuronal calcium transients are brief. The fluorescence response of a $\mathrm{GECl}$ is thus highly dependent 
on its kinetic properties, which are difficult to measure in a physiologically relevant context. Recently, a model of the troponin-C based GECl, TN-L15, proposed a kinetic scheme, rate constants and transfer function between calcium transients and TN-L15 response (Tay et al., 2007). Rather than precisely determine a kinetic scheme for a particular GECl, we construct a simple model to illustrate the dependence of a generic GECl's response on its kinetic rates and other intrinsic properties.

The GECl model is loosely based on G-CaMP2 recordings. All four $\mathrm{Ca}^{2+}$ binding events, the M13 to calmodulin binding event, chromophore activation, and all other conformational shifts leading to fluorescence, are represented in a single transition:

$$
\mathrm{S}+\mathrm{Ca}^{2+} \underset{k_{\text {off }}}{\stackrel{k_{\text {on }}}{\longrightarrow}} \mathrm{S}: \mathrm{Ca}^{2+}
$$

where $S$ represents the unbound, non-fluorescent state, $\mathrm{Ca}^{2+}$ is free calcium and $\mathrm{S}: \mathrm{Ca}^{2+}$ is the bound, fluorescent state. At equilibrium, the fractional saturation state of the $\mathrm{GECl}$ is described by

$$
\begin{gathered}
\Theta=\frac{\left[\mathrm{Ca}^{2+}\right]^{n}}{\left[\mathrm{Ca}^{2+}\right]^{n}+K_{\mathrm{A}}^{n}} \\
K_{\mathrm{A}}=\frac{k_{\text {off }}}{k_{\text {on }}}
\end{gathered}
$$

where $k_{\text {off }}$ and $k_{\text {on }}$ are the rates of fluorescence transition and $K_{\mathrm{A}}$ is the $\left[\mathrm{Ca}^{2+}\right]$ at half maximal fluorescence change. The fluorescence of the $\mathrm{GECl}$ is related to its fractional saturation by

$$
F=\Theta\left(F_{\max }-F_{\min }\right)+F_{\min }
$$

or in terms of fluorescence,

$$
\Theta=\left(\frac{F-F_{\min }}{F_{\max }-F_{\min }}\right)
$$

For FRET and ratiometric single FP reporters, $F$ is analogous to the ratio of the two emission wavelengths.

To quantify dynamics, we represented the change in fractional GECl saturation as the difference between second-order $\mathrm{GECl}-\mathrm{Ca}^{2+}$ association and first-order dissociation:

$$
\frac{\mathrm{d} \Theta}{\mathrm{d} t}=k_{\mathrm{on}}(1-\Theta)\left[\mathrm{Ca}^{2+}\right]-k_{\mathrm{off}}^{\prime} \Theta
$$

To approximate the cooperativity of $\mathrm{GECl}$ fluorescence change, we instantaneously varied the apparent off rate $k_{\text {off }}^{\prime}$ as a function of the fractional saturation:

$$
k_{\mathrm{off}}^{\prime}=k_{\mathrm{off}} \cdot\left(\frac{\Theta}{1-\Theta}\right)^{\frac{1-n}{n}}
$$

for $\Theta<1$.

We simulated the calcium response of a hypothetical $\mathrm{GECl}$ to trains of $1,2,3,4,5,10$, and $40 \mathrm{APs}$, with single-AP $\Delta\left[\mathrm{Ca}^{2+}\right]_{\mathrm{i}}=250 \mathrm{nM}$, $\tau=330 \mathrm{~ms}, \quad[\mathrm{GECl}]=10 \mu \mathrm{M}, \quad n=2.5$ and $F_{\max } / F_{\min }=5$.

We based the kinetic parameters of the model on the best fit to 2-photon imaging of G-CaMP2 in room temperature in utero electroporated acute cortical slice: $K_{\mathrm{A}}=1250 \mathrm{nM}, k_{\mathrm{on}}=8 \times 10^{5} \mathrm{M}^{-1}$ $\mathrm{s}^{-1}$, and $k_{\text {off }}=1 \mathrm{~s}^{-1}$ (Fig. 3a). The deviation between our in vitro affinity estimates and this in situ estimate may be due to endogenous protein interference, incomplete exchange of pipette solution and cytosol, saturation of calcium buffers (Neher, 1998) or release of intracellular calcium stores.

\section{GECI fluorescence properties}

The total dynamic range of a $\mathrm{GECl}$ is defined as the ratio of the signal (fluorescence intensity or acceptor-to-donor emission ratio) of the $\mathrm{Ca}^{2+}$-saturated to the $\mathrm{Ca}^{2+}$-free state. The effective dynamic range is defined as the ratio of the signal in saturating calcium to that at baseline calcium. The SNR, as defined in Eq. 1, scales linearly with effective dynamic range. The dynamic range of currently available GECls has been summarized elsewhere (Garaschuk et al., 2007). The SNR ratio scales as the square root of the number of emitted photons collected, which is closely related to FP intrinsic brightness (extinction coefficient * quantum yield).

Single FP reporters conserve spectral bandwidth, allowing the stacking of additional optical readouts below and above the GFP wavelength. However, measurements must be relative to a baseline as variation in expression or excitation power directly varies fluorescence intensity. Ratiometric measurement of a two-FP GECl makes calcium measurement theoretically independent of expression level or excitation power. It also improves resistance to motion artifacts. In practice, variation in autofluoresence and cell thickness confounds single timepoint ratiometric measurements, particularly under epifluorescence illumination. 
Ratiometric imaging multiplies two independent shot noise components hence is inherently noisier than single-FP imaging at the same brightness. However, FRET-based GECls, TN-XL (Mao et al., 2008), and D3cpv (unpublished observations) expressed in cultured slice are approximately $10 \times$ brighter than G-CaMP2 in the calcium-free state. This brightness may be partially due to higher expression levels, but the intrinsic brightness of the cyan and yellow FP components are much higher than the destabilized GFP of calcium-free GCaMP2. Due to this increased intrinsic brightness, the SNR of TN-XL and D3cpv response will be greater than G-CaMP2 for a given percent signal change.

\section{GECI optimization}

\section{Theoretical improvements}

No single GECl is optimal for all imaging experiments. The appropriate combination of intrinsic GECl parameters must be matched to the extrinsic properties of the system. These extrinsic properties include the size, shape, and the frequency of calcium transients, and baseline $\left[\mathrm{Ca}^{2+}\right]$. Intrinsic GECl parameters include the sensor affinity, kinetics, dynamic range, brightness, expression level, and its independence from endogenous interference.

The relationship between these parameters can be illustrated by their effect on our model GECl. Varying calcium-binding affinity while holding other parameters constant reveals the tradeoffs between detection of short and long spike trains. A high $\mathrm{GECl}$ affinity results in a greater single-AP change in fractional saturation, facilitating detection of single $(250 \mathrm{nM})$ calcium peaks. However, the sensor will saturate more easily, meaning that long spike trains may be poorly resolved. A low affinity provides a baseline $F_{0}$ ( $F$ at resting calcium) closer to $F_{\min }$ ( $F$ at zero calcium), hence a greater effective dynamic range. On the other hand, responses to small transients will be reduced. Keeping [GECl] and $k_{\text {on }}$ constant, fluorescence response to spike trains of $1-40 \mathrm{APs} @ 83 \mathrm{~Hz}$ was modeled as a function of varying $k_{\text {off }}\left(k_{\text {off }}=0.3-\right.$ $30 \mathrm{~s}^{-1} ; K_{\mathrm{A}}=30-3000 \mathrm{nM}$ ) (Fig. 3b). The $K_{\mathrm{A}}$ that maximized $F_{\text {peak }} / F_{0}$ was $180 \mathrm{nM}$ for single APs $\left(\Delta F / F_{0}=0.14\right)$ and $390 \mathrm{nM}$ for 40AP trains $(\Delta F /$ $F_{0}=3.23$ ). Affinity had a greater influence on response of the GECl to $1 \mathrm{AP}$ than to 40AP (Fig. 3b, inset). The model suggests that increasing in situ G-CaMP2 affinity would give a significant increase in SNR. A side effect of reducing $k_{\text {off }}$ is a resulting increase in sensor decay time, making resolution of closely spaced spikes more difficult.

The apparent $\mathrm{GECl} \mathrm{Ca}{ }^{2+}$-binding cooperativity, $n$, strongly affects the optimal affinity predicted by the model (Fig. 3c). A model with large Hill coefficient $(n=2.5)$, as in G-CaMP2, gives an optimal $K_{\mathrm{A}}$ much closer to $\left[\mathrm{Ca}^{2+}\right]_{0}$ than more linear models $\left(n=1\right.$, optimal $\left.K_{\mathrm{A}}=820 \mathrm{nM}\right)$, comparable to in vitro estimates of TN-XXL (Mank and Griesbeck, 2008) and D3cpv affinity (Palmer et al., 2006) (Fig. 3c). High $n$ also provides a higher peak response to a single AP at optimal affinity (Fig. 3c). This advantage is more pronounced with faster kinetics or greater total dynamic range (data not shown). As with high $\mathrm{Ca}^{2+}$-binding affinity, high cooperativity also causes more rapid sensor saturation. It may be preferred for single-spike detection, while systems with tonic or highly modulated activity may best be measured with more linear GECls.

The model also predicts that faster calciumassociation rates will result in greater fluorescence signals. Keeping other model parameters fixed, $k_{\text {off }}$ was varied continuously, and $k_{\text {on }}$ was discretely increased relative to the starting value (Fig. 3d). Increasing the calcium-association rate resulted in slightly higher computed optimal affinity, and significantly larger peak fluorescence response for single transients (Fig. 3d).

Improved fluorescence properties of GECl components will also increase SNR. According to Eq. 1, the SNR of a GECl is linearly dependent on effective dynamic range $\left(F_{\max } / F_{0}\right)$. Since the $F_{0}$ is dependent on the total dynamic range $\left(F_{\max } / F_{\min }\right)$ and the fractional saturation of the sensor at resting calcium (Eq. 9), increasing $F_{\max }$ is more effective at improving effective dynamic range when the fractional saturation at $\left[\mathrm{Ca}^{2+}\right]_{0}$ is close to 0 (Fig. 3e).

Brighter GECl fluorescence yields more photons harvested during imaging, improving SNR (Eq. 1). Photobleaching is of particular concern for two-photon illumination, commonplace for in vivo neuronal imaging. Increased $\mathrm{GECl}$ photostability allows greater laser intensity, producing more photons per second. It can also increase the duration that activity can be continuously monitored. Rapid and complete chromophore maturation at physiological temperature is a prerequisite 
for in vivo functional imaging. Incorporation of FPs with minimal sensitivity to $\mathrm{H}^{+}$and $\mathrm{Cl}^{-}$ions (Tsien, 1998) or to hypothetical FRET quenchers such as ATP (Willemse et al., 2007) may also improve in situ brightness.

\section{Practical improvements}

Troponin C-based GECls such as TN-L15 were designed with the goal of maximizing kinetic rates by use of a fast-binding recognition element (Heim and Griesbeck, 2004). Engineering of two EF hands of TN-L15 produced TN-XL, which shows much faster on and off rates than all other FRETbased GECls, though is not clearly faster than GCaMP1.6 (Mank et al., 2006). TN-XL's affinity is too weak for single AP detection. It has been enhanced by duplication of the higher affinity binding sites in the place of the lower affinity sites, at the cost of some dynamic range, to create TN-XXL (Mank and Griesbeck, 2008).

Many FRET reporters have been improved by substitution of circularly permuted FPs and linker mutagenesis, to optimize excitation and emission dipole orientation (Nagai et al., 2004; Palmer et al., 2006; Mank et al., 2006). To date, the largest observed in vitro FRET ratio change for a linearly fused, reversible FRET indicator is 8-fold in a prototype zinc sensor (Amy Palmer, personal communication), compared to 6.6-fold for YC2.60 and YC3.60, 5.3-fold for D3cpv, 5-fold for TN-XL, and 3.3-fold for TN-XXL (Mank and Griesbeck, 2008). Thus, a 2-fold increase in total dynamic range for FRET-based GECls seems plausible. In the single FP instance, Case-16 shows a 16 -fold $\Delta F / F_{0}$ in vitro (Souslova et al., 2007), 3-fold better than G-CaMP2. If such improvements hold in situ, this will result in significantly better SNR.

Brighter cyan FPs have recently been developed, such as Cerulean (Rizzo et al., 2004) or mTFP (Ai et al., 2008). Substitution of Cerulean for ECFP in cyan-to-yellow FRET sensors has improved SNR (Heim et al., 2007), though this may decrease photostability (Shaner et al., 2005). Alternative FRET pairs using GFP and tdTomato or other coral-derived FPs may have greater brightness, tissue penetration, and photostability (Shaner et al., 2005). In both cases, substitution of these proteins may necessitate sensor re-optimization, as emission dipoles and linker effects can be starkly different even with subtly different FRET pairs (Hires et al., 2008). For single-FP GECls, the extinction coefficient and quantum yield of the saturated state of G-CaMP2 (Tallini et al., 2006) could potentially be increased to the level of EGFP.

GECls ideally should not respond to non-target stimuli such as other divalent cations, which may not correlate with neural activity. Cameleon emission spectra are not directly changed by $\left[\mathrm{Mg}^{2+}\right]$ (Miyawaki et al., 1997), but the effect of $\mathrm{Mg}^{2+}$ on cameleon- $\mathrm{Ca}^{2+}$ titration curves has not been published. $\mathrm{Mg}^{2+}$ may compete with $\mathrm{Ca}^{2+}$ at certain binding sites without inducing a significant conformational change in cameleons. Calcium titration curves of the troponin C-based GECl TN-L15 showed strong $\mathrm{Mg}^{2+}$-sensitivity (Heim and Griesbeck, 2004). Rational engineering of two EF hands within troponin-C produced TN-XL (Mank et al., 2006), with greatly reduced $\mathrm{Mg}^{2+}$-sensitivity. Similarly, GECls should not interact with endogenous calcium-binding proteins. Computational "bumphole" redesign of the calmodulin-M13pep interface within the context of an ECFP-cpVenus FRET sensor produced the D2cpv, D3cpv, and D4cpv class of cameleons (Palmer et al., 2006). These redesigned $\mathrm{GECls}$ performed much better than YC3.3 in membrane-targeted constructs imaged in dissociated hippocampal neurons (Palmer et al., 2006). However, the computational redesign was performed on a significantly different calmodulinbinding peptide than previous cameleons preventing direct comparison.

\section{GECI testing standardization}

The performance of various GECls has been determined in a wide variety of systems. However, comparing their performance between different in vitro, in situ, and various species of in vivo preps is difficult, as each system has substantially different extrinsic parameters. Some diversity in test systems is warranted; performance in mice will depend on different parameters than performance in flies or worms. However, consolidation and standardization of test systems would benefit GECI developers and end-users.

An ideal testing standard should encompass as many aspects of the final measurement system as possible. This standard must be sensitive to both affinity and kinetics. Predicting GECl responses to dynamic calcium transients from equilibrium binding experiments alone is futile. Correspondingly, testing should be done at physiological temperature. The 
calcium transient must be reliably produced and accessible by independent measurement. It should approximate the time course of the signal that ultimately will be measured. If produced by a natural stimulus, the mean and variance of the number of APs it drives and the contribution of synaptic input must be known. To prevent $\mathrm{GECl}$ washout and retain effects of expression and interference, the intracellular milieu should be unperturbed. Practically, the method should retain sufficient throughput to assess newly obtained GECls with minimal delay. It should also be cost-effective and accessible to a large number of imaging and physiology labs.

Most non-neuronal cell types lack sufficient calcium extrusion machinery to rapidly $(\ll 1 \mathrm{~s})$ clear intracellular calcium, making a test in those cells insensitive to sensor kinetics. In dissociated neuronal cultures, the network connectivity and extracellular milieu is dramatically disrupted, which may change the expression patterns of calcium channels and increase response heterogeneity. Cultured slices give anomalously large responses compared to acute slices (Mao et al., 2008). Although cultured neurons can provide a high throughput for screening large numbers of potential sensors, they are imperfect for careful comparison of a small number of high quality sensors.

Recent experiments have established a standard that captures many aspects of in vivo functional imaging of mice. This standard is 2-photon imaging of $\mathrm{GECl}$ responses to back-propagating APs in acute brain slice. The APs are driven by intermittent $2 \mathrm{~ms}$ depolarizing pulses (Pologruto et al., 2004; Mao et al., 2008), or by continuous current injection (Heim et al., 2007) from a patch pipette. Intermittent stimulation offers greater control over spike timing and frequency. Continuous depolarization may cause significant calcium flux during the inter-spike interval, which could overestimate the $\mathrm{GECl}$ response to naturally occurring spike trains. With both techniques, spontaneous activity is silenced with glutamate receptor blockers, so the potential confound of synaptic input is avoided. The calcium transients associated with back-propagating APs have been well characterized, and slice imaging is amenable to $\Delta\left[\mathrm{Ca}^{2+}\right]_{i}$ confirmation with a synthetic dye. Slices can be recorded at room temperature or physiological temperature. Since the $\mathrm{GECl}$ is expressed from a prenatal period, developmental and interference effects will be captured. Recording can be done with high-resistance electrodes or via perforated patch to reduce or prevent dialysis of intracellular components.

This technique has a moderate throughput. In conjunction with in utero electroporation, acute slice imaging allows thorough characterization of around two GECls per person, per week. The delay between plasmid construction and response characterization is 3 weeks. Excluding the fixed costs of an imaging and physiology rig, testing of novel GECls via in utero electroporation is inexpensive compared to virus or transgenic animal production.

There are a few parameters that this method does not fully capture. In utero electroporation does not drive very high expression levels. In neurons that highly expressed G-CaMP2, sensor invaded the nucleus and performance was poor (data not shown). GECls with reduced interference, such as $\mathrm{TN}-\mathrm{XXL}$ or $\mathrm{D} 3 \mathrm{cpv}$, might show higher relative performance when driven by powerful promoters introduced by virus. In vivo imaging has more challenging SNR requirements due to greater imaging depth and motion artifacts. However, mice from the same litter of in utero electroporated animals can be simultaneously tested in brain slice and in vivo preps. This can easily confirm the predictive power of this testing method.

\section{Combined optical stimulation and recording}

Genetically encoded optical tools for the control of membrane potential have improved dramatically over the past several years. However, the action spectrum of the neuronal activating channelrhodopsin-2 (ChR2) (Zhang et al., 2006) and neuronal silencing halorhodopsin (NpHR) (Han and Boyden, 2007; Zhang et al., 2007) overlap with the excitation or emission spectra of currently available GECls. Far red-shifted variants of ChR2 may permit continuous monitoring of calcium responses during stimulation (Zhang et al., 2008). However, these variants are still in developmental stages and have not been well characterized in in vivo systems. Gated illumination protocols should allow combined neuronal stimulation with GECl monitoring using standard ChR2 and any major class of GECl.

ChR2 requires a brief pulse (1-10 ms) of spatially broad, bright illumination to induce AP firing. At light intensities used for calcium imaging, 
two-photon laser scanning illumination of ChR2 does not cause membrane depolarization (Zhang and Oertner, 2007). Calcium transients persist for hundreds of milliseconds and are typically acquired at $4-8 \mathrm{~Hz}$ in vivo. Two-photon laser scanning can be used to excite the $\mathrm{GECl}$, widefield blue light used to stimulate $\mathrm{ChR} 2$, and the $\mathrm{GECl}$ emission channels can be gated during the ChR2 stimulation pulses. Precise gating during a 1AP stimulation will cause a loss of GECl signal from only a small fraction of the field of view for a single timepoint.

Since neuronal silencing via NpHR requires continuous illumination, gating during optical silencing will have a greater impact on GECI signal collection. However, NpHR's action spectrum extends to wavelengths longer than $600 \mathrm{~nm}$ (Han and Boyden, 2007). Simultaneous two-photon imaging of a $\mathrm{GECl}$ during long wavelength excitation of NpHR should be possible with appropriate selection of interference filters. This could also be combined with ChR2 gating for bi-directional optical neuronal control and recording.

\section{In vivo imaging}

What level of improvement in SNR of currently available GECls is needed to reliably detect single APs in vivo? Currently, the response to single APs of G-CaMP2 or TN-XL is buried in the noise floor of acute slice (Figs. 2a, b, and 3a) (Mao et al., 2008; Heim et al., 2007). In cultured slice at room temperature, a burst of four APs at $83 \mathrm{~Hz}$ was required for $>90 \%$ reliable detection of G-CaMP2 signal, while 10 AP were required at $35^{\circ} \mathrm{C}$ (Mao et al., 2008). Both burst conditions had an average peak $\Delta F / F_{0}$ of approximately $60 \%$, with the smallest detectable response of approximately $30 \% \Delta F / F_{0}$ (Mao et al., 2008). Brighter GECls, such as D3cpv and TnC-based sensors should have significantly lower thresholds, due to reduced noise. In acute cortical slice from transgenic CerTN-L15 mice, continuous current injections that caused a two AP burst gave $\Delta R / R_{0}$ of $13 \%$. These were detectable, though reliability statistics were not published (Heim et al., 2007).

The noise level in vivo is generally worse than in brain slice. It is dependent on specifics of the imaging setup, on GECl brightness, expression level, and cell depth, so determining the exact amount of improvement needed for reliable single
AP detection is impossible. As a rough guide, glutamate-induced dendritic transients of CerTNL15 in vivo had a $\Delta R / R_{0}$ of $49 \%$ and peak-to-peak noise of approximately $15 \%$ in single trials (Heim et al., 2007). The effects of various GECl improvements on reaching in vivo detection thresholds are predictable. Kinetic rates of most biological processes increase between room temperature and $37^{\circ} \mathrm{C}$. Peak G-CaMP2 responses recorded at $35^{\circ} \mathrm{C}$ in acute slice are reported to be reduced by about $50 \%$ in amplitude and have $~ 3$-fold faster decay time than at $22^{\circ} \mathrm{C}$ (Mao et al., 2008). The faster decay is likely due to a combination of an increase in speed of the underlying transient, due to faster calcium extrusion, and an increase in G-CaMP2 kinetics. The reduction in peak response suggests that the temperature dependence of $\mathrm{Ca}^{2+}$-binding to G-CaMP2 is less than that of the calcium extrusion rate. Using calcium transients from dendritic measurements made at physiological temperatures ( $\tau=70 \mathrm{~ms}$ ) (Markram et al., 1995) reduces the $1 \mathrm{AP}$ response of an optimal affinity $\mathrm{GECl}$ from 0.14 to $0.04 \Delta F / F_{0}$, assuming no corresponding increase in $\mathrm{GECl}$ kinetics (Fig. 3f). A plausible future improvement of $F_{\text {max }} / F_{\text {min }}$ to 15 fold increases the response to $0.12 \Delta F / F_{0}$. As $\mathrm{GECl}$ kinetic rates increase, either through the temperature dependence or engineering, the $1 \mathrm{AP}$ response reaches levels that should allow reliable in vivo detection (Fig. 3f), with the exact threshold determined by brightness and expression level. Although there is no single "magic bullet" to make GECls reach performance levels equivalent to synthetic indicators, concerted optimization of the numerous factors explored here provides a plausible route to consistent single AP detection.

\section{Conclusion}

GECls have come a long way in the decade since their creation; nearly every relevant biophysical parameter has been improved relative to the first generation. Increases in baseline brightness and relative signal change have contributed to enhanced SNR ratio. Rational engineering of GECI components has produced variants with decreased interaction with endogenous proteins, facilitating long-term imaging experiments at higher expression levels with fewer non-target effects. Concomitant with sensor improvements, systematic 
optimization of data collection, filtering, and analysis techniques has improved spike detection (Yaksi and Friedrich, 2006). Several classes of GECls have performed well for neural imaging, encompassing single-FP and FRET sensors, and sensors based on calmodulin and troponin- $C$ calcium-binding domains. Published GECls are adequate for detecting high frequency bursts of neuronal activity, making them appropriate for activity localization in mouse myotubes (Nakai et al., 2001), mouse cerebellum (Diez-Garcia et al., 2005), or in invertebrate systems (Kerr et al., 2000; Higashijima et al., 2003; Wang et al., 2003; Chronis et al., 2007; Clark et al., 2007). However, reliable in vivo single-AP detection is not yet feasible with the current generation of techniques. For the moment, projects seeking to image sparsely encoded information will best be served by bulk loading of small molecule dyes, despite the limitations of an acute time course, difficult loading, poor cellular specificity, and neuropil signal contamination (Kerr and Denk, 2008).

Future protein engineering efforts will primarily focus on improving GECl SNR. Incremental increases to existing GECls appear sufficient to reach single-AP detection, but novel scaffolds may be found with even greater performance. Structural analysis of GECls via X-ray crystallography or NMR may help elucidate their $\mathrm{Ca}^{2+}$. dependent reporting mechanism, particularly if structural information can be obtained in both the $\mathrm{Ca}^{2+}$-free and $\mathrm{Ca}^{2+}$-bound states. This could aid in the optimization of existing sensors and the engineering of new ones. It must also be ensured that GECls are amenable to long-term expression and imaging in animals. This may involve iterative negative design against endogenous interactions and use of inducible, reversible promoters (Hasan et al., 2004).

GECls must be prototyped in a way that will accurately predict their performance in functional imaging studies. Broad use of a standard assay in a well-defined biological system will ensure that the best GECls are prioritized for further testing and eventual construction of transgenic lines. Systematic optimization of individual sensor components, allosteric response mechanisms, and overall performance in a realistic assay, will lead to dramatic improvements in many $\mathrm{GECl}$ formats in the near term. The goal of imaging sparse firing in vivo with GECls requires much work, but the prospect of long-term, high resolution, non-invasive in vivo functional imaging in defined cell populations guarantees that it will be worth the effort.

\section{Methods}

In vitro characterization-G-CaMP2 was expressed in Escherichia coli BL21 (DE3) using a pRSETB plasmid, and purified via a 6His-NiNTA system. Following buffer exchange to $100 \mathrm{mM} \mathrm{NaCl}, 20 \mathrm{mM}$ Tris, $\mathrm{pH} 7.5$, protein was diluted $\sim 200$-fold to $1 \mu \mathrm{M}$ [G-CaMP2] in a historical buffer of $100 \mathrm{mM} \mathrm{KCl}$, $30 \mathrm{mM}$ MOPS, $\mathrm{pH} 7.5$, or mock internal solution of $135 \mathrm{mM} \mathrm{KCl}, 0-4 \mathrm{mM} \mathrm{MgCl}_{2}, 10 \mathrm{mM}$ HEPES, $3 \mathrm{mM}$ Na-ascorbate, $\mathrm{pH}$ 7.3. These solutions were supplemented with a $10 \mathrm{mM}$ blend of $\mathrm{K}_{2} \mathrm{H}_{2}$ EGTA and CaEGTA from the concentrated Calcium Calibration Kit (Invitrogen) in various ratios to control free calcium concentration. The $\mathrm{pH}$ probe was calibrated and solution acidity adjusted with small volumes of $\mathrm{KOH}$ and $\mathrm{HCl}$ while submerged in a water bath maintained at $28^{\circ} \mathrm{C}$. Four sets of titration points for each condition were measured three times on a Safire ${ }^{2}$ fluorescence plate reader (Tecan) with excitation at $470 \mathrm{~nm}$ and emission at $510 \mathrm{~nm}$, bandwidth $15 \mathrm{~nm}$, then averaged.

To estimate intracellular [G-CaMP2], purified G-CaMP2 in pipette internal solution supplemented with $1 \mathrm{mM} \mathrm{K} \mathrm{K}_{2}$ EGTA was drawn into thin glass capillaries (ID $=0.02 \mathrm{~mm}$, Vitrocom \#RT5002) at $0.1,1$, and $10 \mu \mathrm{M}$ concentrations. Their fluorescence intensity was measured under 2-photon excitation parameters identical $(910 \mathrm{~nm})$ to slice imaging. These intensities were compared to those of the recorded G-CaMP2 cells. Expression was estimated by assuming fluorescence per molecule of G-CaMP2 was identical between purified and intracellular G-CaMP2.

\section{Slice preparation and recording}

In utero electroporation and acute slice preparation was done as previously described (Mao et al., 2008). After $1 \mathrm{~h}$ pre-incubation, slices were transferred to an immersion-type recording chamber and perfused with ACSF comprising (in $\mathrm{mM}$ ) $127 \mathrm{NaCl}$, $2.5 \mathrm{KCl}, 1.25 \mathrm{NaH}_{2} \mathrm{PO}_{4}, 25$ D-glucose, $25 \mathrm{NaHCO}_{3}$, $4 \mathrm{CaCl}_{2}$, and $4 \mathrm{MgCl}_{2}$ saturated with $95 \% \mathrm{O}_{2} / 5 \%$ $\mathrm{CO}_{2}$ and with $25 \mu \mathrm{M}(\mathrm{R})$-CPP (Tocris) and $25 \mu \mathrm{M}$ NBQX (Sigma) to block glutamate receptors. Recordings were performed at room temperature $\left(22^{\circ} \mathrm{C}\right)$. Neurons were visualized under infrared 
differential interference optics and patched with borosilicate pipettes (resistance 4-6 M 2 ). The intracellular solution contained (in mM) $128 \mathrm{~K}$-gluconate, 10 HEPES, $10 \quad \mathrm{Na}_{2}$-phosphocreatine, 4 $\mathrm{Na}_{2}$-ATP, $0.4 \mathrm{Na}-\mathrm{GTP}, 4 \mathrm{MgCl}_{2}, 0.4 \mathrm{Na}_{2}$-GTP, and 3 Na-ascorbate (pH 7.27; 287 mOsm). Cells were recorded at a depth of 50-95 $\mu \mathrm{m}$ in the brain slice.

Imaging was performed as previously described (Mao et al., 2008). Neurons were imaged in linescan mode $(500 \mathrm{~Hz})$ across a location $20-40 \mu \mathrm{m}$ from the base of the apical dendrite using 2-photon excitation from a Ti:sapphire laser (Mira, Coherent, Santa Clara, CA, USA) tuned to $910 \mathrm{~nm}$. Fluorescence was collected in two channels in both epi- and trans-fluorescence mode using four photomultiplier tubes (Hamamatsu, Hamamatsu City, Japan), then separated into green and red channels with $565 \mathrm{~nm}$ dichroics and BG22 (green) and HQ620/90 (red) emission filters. PMT dark noise was subtracted from all traces. Crosstalk between emission channels was negligible. Peak fluorescence was determined by averaging $30 \mathrm{~ms}$ of the raw fluorescence time series about the peak of the trace linearly filtered at $30 \mathrm{~Hz}$. Data were acquired and analyzed with custom Matlab software (Mathworks).

\section{GECI modeling}

Simulations of calcium transients and GECI response were performed in Matlab. Euler's method was used for time discretization with a time step of $20 \mu \mathrm{s}$. Matlab notebooks used for modeling calcium transients and GECI responses are available on the Brain Cell Biology website.

\section{Acknowledgments}

We thank Chris Harvey, Tianyi Mao, Haining Zhong, and Jasper Akerboom for technical assistance and Karel Svoboda for use of equipment, helpful discussions, and comments on the manuscript. This work was supported by the Howard Hughes Medical Institute.

\section{Open Access}

This article is distributed under the terms of the Creative Commons Attribution Noncommercial
License which permits any noncommercial use, distribution, and reproduction in any medium, provided the original author(s) and source are credited.

\section{References}

Ai, H. W., Olenych, S. G., Wong, P., Davidson, M. W., and Campbell, R. E. (2008). Hue-shifted monomeric variants of Clavularia cyan fluorescent protein: identification of the molecular determinants of color and applications in fluorescence imaging. BMC Biol. 6, 13.

Baird, G. S., Zacharias, D. A., and Tsien, R. Y. (1999). Circular permutation and receptor insertion within green fluorescent proteins. Proc. Natl Acad. Sci. USA 96, 11241-11246.

Burgoyne, R. D. (2007). Neuronal calcium sensor proteins: generating diversity in neuronal Ca2+ signalling. Nat. Rev. Neurosci. 8, 182193.

Chronis, N., Zimmer, M., and Bargmann, C. I. (2007). Microfluidics for in vivo imaging of neuronal and behavioral activity in Caenorhabditis elegans. Nat. Method. 4, 727-731.

Clark, D. A., Gabel, C. V., Gabel, H., and Samuel, A. D. (2007). Temporal activity patterns in thermosensory neurons of freely moving Caenorhabditis elegans encode spatial thermal gradients. J. Neurosci. 27, 6083-6090.

Denk, W., Yuste, R., Svoboda, K., and Tank, D. W. (1996). Imaging calcium dynamics in dendritic spines. Curr. Opin. Neurobiol. 6, 372-378.

Di Virgilio, F., Steinberg, T. H., Swanson, J. A., and Silverstein, S. C. (1988). Fura-2 secretion and sequestration in macrophages. A blocker of organic anion transport reveals that these processes occur via a membrane transport system for organic anions. J. Immunol. 140, 915-920.

Diez-Garcia, J., Matsushita, S., Mutoh, H., Nakai, J., Ohkura, M., Yokoyama, J. et al. (2005). Activation of cerebellar parallel fibers monitored in transgenic mice expressing a fluorescent $\mathrm{Ca}^{2+}$ indicator protein. Eur. J. Neurosci. 22, 627-635.

Ferkey, D. M., Hyde, R., Haspel, G., Dionne, H. M., Hess, H. A., Suzuki, H. et al. (2007). C. elegans $G$ protein regulator RGS-3 controls sensitivity to sensory stimuli. Neuron $53,39-52$. 
Fiala, A., Spall, T., Diegelmann, S., Eisermann, B., Sachse, S., Devaud, J. M. et al. (2002). Genetically expressed cameleon in Drosophila melanogaster is used to visualize olfactory information in projection neurons. Curr. Biol. 12, 1877-1884.

Furler, S., Paterna, J. C., Weibel, M., and Bueler, $H$. (2001). Recombinant AAV vectors containing the foot and mouth disease virus $2 \mathrm{~A}$ sequence confer efficient bicistronic gene expression in cultured cells and rat substantia nigra neurons. Gene Ther. 8, 864-873.

Garaschuk, O., Griesbeck, O., and Konnerth, A. (2007). Troponin C-based biosensors: a new family of genetically encoded indicators for in vivo calcium imaging in the nervous system. Cell Calcium 42, 351-361.

Grynkiewicz, G., Poenie, M., and Tsien, R. Y. (1985). A new generation of $\mathrm{Ca}^{2+}$ indicators with greatly improved fluorescence properties. J. Biol. Chem. 260, 3440-3450.

Han, X. and Boyden, E. S. (2007). Multiple-color optical activation, silencing, and desynchronization of neural activity, with single-spike temporal resolution. PLoS ONE 2, e299.

Hasan, M. T., Friedrich, R. W., Euler, T., Larkum, M. E., Giese, G., Both, M. et al. (2004). Functional fluorescent $\mathrm{Ca}^{2+}$ indicator proteins in transgenic mice under TET control. PLoS Biol. 2, e163.

Haugland, R. P., Spence, M. T. Z., Johnson, I. D., and Basey, A. (2005). The Handbook: A Guide to Fluorescent Probes and Labeling Technologies, 10th ed., Molecular Probes, Eugene, OR.

Heim, N. and Griesbeck, O. (2004). Genetically encoded indicators of cellular calcium dynamics based on troponin $\mathrm{C}$ and green fluorescent protein. J. Biol. Chem. 279, 14280-14286.

Heim, N., Garaschuk, O., Friedrich, M. W., Mank, M., Milos, R. I., Kovalchuk, Y. et al. (2007). Improved calcium imaging in transgenic mice expressing a troponin C-based biosensor. Nat. Method 4, 127-129.

Helmchen, F., Imoto, K., and Sakmann, B. (1996). $\mathrm{Ca}^{2+}$ buffering and action potential-evoked $\mathrm{Ca}^{2+}$ signaling in dendrites of pyramidal neurons. Biophys. J. 70, 1069-1081.

Higashijima, S., Masino, M. A., Mandel, G., and Fetcho, J. R. (2003). Imaging neuronal activity during zebrafish behavior with a genetically encoded calcium indicator. J. Neurophysiol. 90, 3986-3997.
Hille, B. (1992). Ionic Channels of Excitable Membranes, 2nd. ed., Sinauer Associates, Sunderland, MA.

Hires, S. A., Zhu, Y., and Tsien, R. Y. (2008). Optical measurement of synaptic glutamate spillover and reuptake by linker optimized glutamate-sensitive fluorescent reporters. Proc. Natl. Acad. Sci. USA 105, 4411-4416.

Jaffe, D. B., Johnston, D., Lasser-Ross, N., Lisman, J. E., Miyakawa, H., and Ross, W. N. (1992). The spread of $\mathrm{Na}+$ spikes determines the pattern of dendritic $\mathrm{Ca}^{2+}$ entry into hippocampal neurons. Nature 357, 244-246.

Jayaraman, V., and Laurent, G. (2007). Evaluating a genetically encoded optical sensor of neural activity using electrophysiology in intact adult fruit flies. Front. Neural Circ. 1. doi:10.3389/ neuro.04.003.2007.

Johnson, F. H. and Shimomura, O. (1972). Preparation and use of aequorin for rapid microdetermination of $\mathrm{Ca}^{2+}$ in biological systems. Nat. New. Biol. 237, 287-288.

Kerr, J. N. and Denk, W. (2008). Imaging in vivo: watching the brain in action. Nat. Rev. Neurosci. 9, 195-205.

Kerr, R., Lev-Ram, V., Baird, G., Vincent, P., Tsien, R. Y., and Schafer, W. R. (2000). Optical imaging of calcium transients in neurons and pharyngeal muscle of $C$. elegans. Neuron 26, 583-594.

Kerr, R. A. and Schafer, W. R. (2006). Intracellular $\mathrm{Ca}^{2+}$ imaging in C. elegans. Method. Mol. Biol. 351, 253-264.

Kindt, K. S., Quast, K. B., Giles, A. C., De, S., Hendrey, D., Nicastro, I. et al. (2007). Dopamine mediates context-dependent modulation of sensory plasticity in C. elegans. Neuron 55 , 662-676.

Kotlikoff, M. I. (2007). Genetically encoded $\mathrm{Ca}^{2+}$ indicators: using genetics and molecular design to understand complex physiology. J. Physiol. 578, 55-67.

Linse, S., Helmersson, A., and Forsen, S. (1991). Calcium binding to calmodulin and its globular domains. J. Biol. Chem. 266, 8050-8054.

Llinas, R., Sugimori, M., and Simon, S. M. (1982). Transmission by presynaptic spike-like depolarization in the squid giant synapse. Proc. Natl. Acad. Sci. USA 79, 2415-2419.

Mank, M., and Griesbeck, O. (2008). Genetically encoded calcium indicators. Chem. Rev. 108, 1550-1564. 
Mank, M., Reiff, D. F., Heim, N., Friedrich, M. W., Borst, A., and Griesbeck, O. (2006). A FRETbased calcium biosensor with fast signal kinetics and high fluorescence change. Biophys. J. 90, 1790-1796.

Mao, T., O'Connor, D. H., Scheuss, V., Nakai, J., and Svoboda, K. (2008). Characterization and subcellular targeting of GCaMP-type genetically-encoded calcium indicators. PLoS ONE 3, e1796.

Markram, H. and Sakmann, B. (1994). Calcium transients in dendrites of neocortical neurons evoked by single subthreshold excitatory postsynaptic potentials via low-voltage-activated calcium channels. Proc. Natl. Acad. Sci. USA 91, 5207-5211.

Markram, H., Helm, P. J., and Sakmann, B. (1995). Dendritic calcium transients evoked by single back-propagating action potentials in rat neocortical pyramidal neurons. J. Physiol. 485, 120.

Minta, A., Kao, J. P., and Tsien, R. Y. (1989). Fluorescent indicators for cytosolic calcium based on rhodamine and fluorescein chromophores. J. Biol. Chem. 264, 8171-8178.

Miyawaki, A. and Tsien, R. Y. (2000). Monitoring protein conformations and interactions by fluorescence resonance energy transfer between mutants of green fluorescent protein. Method. Enzymol. 327, 472-500.

Miyawaki, A., Llopis, J., Heim, R., McCaffery, J. M., Adams, J. A., Ikura, M. et al. (1997). Fluorescent indicators for $\mathrm{Ca}^{2+}$ based on green fluorescent proteins and calmodulin. Nature 388, 882-887.

Miyawaki, A., Griesbeck, O., Heim, R., and Tsien, R. Y. (1999). Dynamic and quantitative $\mathrm{Ca}^{2+}$ measurements using improved cameleons. Proc. Natl. Acad. Sci. USA 96, 2135-2140.

Muller, W. and Connor, J. A. (1991). Dendritic spines as individual neuronal compartments for synaptic $\mathrm{Ca}^{2+}$ responses. Nature 354, 73-76.

Nagai, T., Sawano, A., Park, E. S., and Miyawaki, A. (2001). Circularly permuted green fluorescent proteins engineered to sense $\mathrm{Ca}^{2+}$. Proc. Natl. Acad. Sci. USA 98, 3197-3202.

Nagai, T., Yamada, S., Tominaga, T., Ichikawa, M., and Miyawaki, A. (2004). Expanded dynamic range of fluorescent indicators for $\mathrm{Ca}^{2+}$ by circularly permuted yellow fluorescent proteins. Proc. Natl. Acad. Sci. USA 101, 10554-10559.
Nakai, J., Ohkura, M., and Imoto, K. (2001). A high signal-to-noise $\mathrm{Ca}(2+)$ probe composed of a single green fluorescent protein. Nat. Biotechnol. 19, 137-141.

Neher, E. (1995). The use of fura-2 for estimating $\mathrm{Ca}$ buffers and $\mathrm{Ca}$ fluxes. Neuropharmacology $34,1423-1442$.

Neher, E. (1998). Usefulness and limitations of linear approximations to the understanding of $\mathrm{Ca}^{++}$signals. Cell Calcium 24, 345-357.

Ogawa, Y. and Tanokura, M. (1984). Calcium binding to calmodulin: effects of ionic strength, $\mathrm{Mg} 2+, \mathrm{pH}$ and temperature. J. Biochem. 95, 19-28.

Ohkura, M., Matsuzaki, M., Kasai, H., Imoto, K., and Nakai, J. (2005). Genetically encoded bright $\mathrm{Ca}^{2+}$ probe applicable for dynamic $\mathrm{Ca}^{2+}$ imaging of dendritic spines. Anal. Chem. 77, 5861-5869.

Palmer, A. E. and Tsien, R. Y. (2006). Measuring calcium signaling using genetically targetable fluorescent indicators. Nat. Protoc. 1, 10571065.

Palmer, A. E., Giacomello, M., Kortemme, T., Hires, S. A., Lev-Ram, V., Baker, D. et al. (2006). $\mathrm{Ca}^{2+}$ indicators based on computationally redesigned calmodulin-peptide pairs. Chem. Biol. 13, 521-530.

Pelletier, J. and Sonenberg, N. (1988). Internal initiation of translation of eukaryotic mRNA directed by a sequence derived from poliovirus RNA. Nature 334, 320-325.

Pologruto, T. A., Yasuda, R., and Svoboda, K. (2004). Monitoring neural activity and $\left[\mathrm{Ca}^{2+}\right]$ with genetically encoded $\mathrm{Ca}^{2+}$ indicators. J. Neurosci. 24, 9572-9579.

Reiff, D. F., Ihring, A., Guerrero, G., Isacoff, E. Y., Joesch, M., Nakai, J. et al. (2005). In vivo performance of genetically encoded indicators of neural activity in flies. J. Neurosci. 25, 47664778.

Rink, T. J., Tsien, R. Y., and Warner, A. E. (1980). Free calcium in Xenopus embryos measured with ion-selective microelectrodes. Nature 283, 658-660.

Rizzo, M. A., Springer, G. H., Granada, B., and Piston, D. W. (2004). An improved cyan fluorescent protein variant useful for FRET. Nat. Biotechnol. 22, 445-449.

Schiller, J., Helmchen, F., and Sakmann, B. (1995). Spatial profile of dendritic calcium transients 
evoked by action potentials in rat neocortical pyramidal neurones. J. Physiol. 487, 583-600.

Shaner, N. C., Steinbach, P. A., and Tsien, R. Y. (2005). A guide to choosing fluorescent proteins. Nat. Method. 2, 905-909.

Shimozono, S. and Miyawaki, A. (2008). Engineering FRET constructs using CFP and YFP. Method. Cell Biol. 85, 381-393.

Souslova, E. A., Belousov, V. V., Lock, J. G., Stromblad, S., Kasparov, S., Bolshakov, A. P. et al. (2007). Single fluorescent protein-based $\mathrm{Ca}^{2+}$ sensors with increased dynamic range. BMC Biotechnol. 7, 37.

Suzuki, H., Kerr, R., Bianchi, L., Frokjaer-Jensen, C., Slone, D., Xue, J. et al. (2003). In vivo imaging of $C$. elegans mechanosensory neurons demonstrates a specific role for the MEC4 channel in the process of gentle touch sensation. Neuron 39, 1005-1017.

Tallini, Y. N., Ohkura, M., Choi, B. R., Ji, G., Imoto, K., Doran, R. et al. (2006). Imaging cellular signals in the heart in vivo: cardiac expression of the high-signal $\mathrm{Ca}^{2+}$ indicator GCaMP2. Proc. Natl. Acad. Sci. USA 103, 4753-4758.

Tay, L. H., Griesbeck, O., and Yue, D. T. (2007). Live-cell transforms between $\mathrm{Ca}^{2+}$ transients and FRET responses for a troponin-C-based $\mathrm{Ca}^{2+}$ sensor. Biophys. J. 93, 4031-4040.

Tour, O., Adams, S. R., Kerr, R. A., Meijer, R. M., Sejnowski, T. J., Tsien, R. W. et al. (2007). Calcium Green FIAsH as a genetically targeted small-molecule calcium indicator. Nat. Chem. Biol. 3, 423-431.

Truong, K., Sawano, A., Miyawaki, A., and Ikura, M. (2007). Calcium indicators based on calmodulin-fluorescent protein fusions. Methods Mol. Biol. 352, 71-82.

Tsai, P. S., Friedman, B., Ifarraguerri, A. I., Thompson, B. D., Lev-Ram, V., Schaffer, C. B. et al. (2003). All-optical histology using ultrashort laser pulses. Neuron 39, 27-41.

Tsien, R. Y. (1980). New calcium indicators and buffers with high selectivity against magnesium and protons: design, synthesis, and properties of prototype structures. Biochemistry 19, 2396-2404.

Tsien, R. Y. (1998). The green fluorescent protein. Annu. Rev. Biochem. 67, 509-544.

Tsien, R. Y. (1999). Monitoring cell calcium. In: Carafoli, E., Klee, C. B. (eds.) Calcium as a cellular regulator, Oxford University Press, USA, pp. 28-54.
Tsien, R. Y. and Rink, T. J. (1983). Measurement of cytoplasmic free $\mathrm{Ca}^{2+}$. In: Barker, J., McKelvey, J. F. (eds.) Current Methods of Cellular Neurobiology, 3rd. ed., Wiley, New York.

Wang, J. W., Wong, A. M., Flores, J., Vosshall, L. B., and Axel, R. (2003). Two-photon calcium imaging reveals an odor-evoked map of activity in the fly brain. Cell 112, 271-282.

Willemse, M., Janssen, E., de Lange, F., Wieringa, B., and Fransen, J. (2007). ATP and FRET-a cautionary note. Nat. Biotechnol. 25, 170-172.

Yaksi, E. and Friedrich, R. W. (2006). Reconstruction of firing rate changes across neuronal populations by temporally deconvolved $\mathrm{Ca}^{2+}$ imaging. Nat. Method. 3, 377-383.

Yang, Y., Costa, A., Leonhardt, N., Siegel, R. S., and Schroeder, J. I. (2008). Isolation of a strong Arabidopsis guard cell promoter and its potential as a research tool. Plant Method. 4, 6 .

Yasuda, R., Nimchinsky, E. A., Scheuss, V., Pologruto, T. A., Oertner, T. G., Sabatini, B. L., et al. (2004). Imaging calcium concentration dynamics in small neuronal compartments. Sci. STKE 2004, 15.

Yuste, R. and Denk, W. (1995). Dendritic spines as basic functional units of neuronal integration. Nature 375, 682-684.

Yuste, R., Majewska, A., Cash, S. S., and Denk, W. (1999). Mechanisms of calcium influx into hippocampal spines: heterogeneity among spines, coincidence detection by NMDA receptors, and optical quantal analysis. J. Neurosci. 19, 1976-1987.

Zhang, Y. P. and Oertner, T. G. (2007). Optical induction of synaptic plasticity using a lightsensitive channel. Nat. Method. 4, 139-141.

Zhang, F., Wang, L. P., Boyden, E. S., and Deisseroth, K. (2006). Channelrhodopsin-2 and optical control of excitable cells. Nat. Method. 3, 785-792.

Zhang, F., Wang, L. P., Brauner, M., Liewald, J. F., Kay, K., Watzke, N. et al. (2007). Multimodal fast optical interrogation of neural circuitry. Nature 446, 633-639.

Zhang, F., Prigge, M., Beyriere, F., Tsunoda, S. P., Mattis, J., Yizhar, O. et al. (2008). Red-shifted optogenetic excitation: a tool for fast neural control derived from Volvox carteri. Nat. Neurosci. 11, 631-633. 